\title{
Vibrio vulnificus MARTX cytotoxin causes inactivation of phagocytosis-related signaling molecules in macrophages
}

\author{
Chun-Liang Chen', Shu-Chun Chien', Tzeng-Horng Leu ${ }^{2,3}$, Hans I-Chen Harn², Ming-Jer Tang ${ }^{2,4}$ and Lien-I Hor ${ }^{1,2^{*}}$ (D)
}

\begin{abstract}
Background: Vibrio vulnificus is a marine bacterial species that causes opportunistic infections manifested by serious skin lesions and fulminant septicemia in humans. We have previously shown that the multifunctional autoprocessing repeats in toxin $\left(M_{A R T X_{V} 1}\right.$ ) of a biotype $1 \mathrm{~V}$. vulnificus strain promotes survival of this organism in the host by preventing it from engulfment by the phagocytes. The purpose of this study was to further explore how MARTX $V_{V 1}$ inhibits phagocytosis of this microorganism by the macrophage.
\end{abstract}

Methods: We compared between a wild-type $V$. vulnificus strain and its MARTX $\mathrm{VV}_{V 1}$-deficient mutant for a variety of phagocytosis-related responses, including morphological change and activation of signaling molecules, they induced in the macrophage. We also characterized a set of MARTX ${ }_{V v 1}$ domain-deletion mutants to define the regions associated with antiphagocytosis activity.

Results: The RAW 264.7 cells and mouse peritoneal exudate macrophages underwent cell rounding accompanied by F-actin disorganization in the presence of MARTX $\mathrm{VV}_{V}$. In addition, phosphorylation of some F-actin rearrangementassociated signaling molecules, including Lyn, Fgr and Hck of the Src family kinases (SFKs), focal adhesion kinase (FAK), proline-rich tyrosine kinase 2 (Pyk2), phosphoinositide 3-kinase (PI3K) and Akt, but not p38, was decreased. By using specific inhibitors, we found that these kinases were all involved in the phagocytosis of MARTX $V_{V 1}$-deficient mutant in an order of SFKs-FAK/Pyk2-PI3K-Akt. Deletion of the effector domains in the central region of MARTX $X_{V 1}$ could lead to reduced cytotoxicity, depending on the region and size of deletion, but did not affect the antiphagocytosis activity and ability to cause rounding of macrophage. Reduced phosphorylation of Akt was closely associated with inhibition of phagocytosis by the wild-type strain and MARTX $\mathrm{vv}_{\mathrm{v}}$ domain-deletion mutants, and expression of the constitutively active Akt, myr-Akt, enhanced the engulfment of these strains by macrophage.

Conclusions: MARTX ${ }_{V 1}$ could inactivate the SFKs-FAK/Pyk2-PI3K-Akt signaling pathway in the macrophages. This might lead to impaired phagocytosis of the $V$. vulnificus-infected macrophage. The majority of the central region of MARTX $_{\mathrm{V} 1}$ is not associated with the antiphagocytosis activity.

Keywords: Vibrio vulnificus, MARTX, Antiphagocytosis, Cell rounding, Signaling pathway, Domain-deletion mutants

\footnotetext{
* Correspondence: h061453@mail.ncku.edu.tw

'Department of Microbiology and Immunology, College of Medicine,

National Cheng Kung University, Tainan 70101, Taiwan

${ }^{2}$ Institute of Basic Medical Sciences, College of Medicine, National Cheng

Kung University, Tainan 70101, Taiwan

Full list of author information is available at the end of the article
} 


\section{Background}

Vibrio vulnificus is a gram-negative bacillus distributed worldwide in estuaries. Strains of this species are currently divided into biotypes 1, 2 and 3 based on their biochemical traits and host range $[1,2]$. Biotype $1 \mathrm{~V}$. vulnificus comprises most of the clinical and environmental isolates, and may cause serious skin lesions and/or fulminant septicemia in humans contracting this organism via wounds or ingestion of contaminated seafood [3]. Most patients have underlying diseases, particularly chronic liver disorders, and the mortality rate may exceed $50 \%$ [3]. A number of virulence factors have been identified in $V$. vulnificus, including capsular polysaccharides [4], iron-acquisition ability $[5,6]$, flagellum [7], type IV pili [8], extracellular insulin-degrading enzyme [9] and an RTX (repeats in toxin) cytotoxin [10-12].

The RTX toxins are produced by a variety of gramnegative bacterial pathogens, and are characterized by large size (over $100 \mathrm{kDa}$ ), the glycine and aspartate-rich (GD-rich) nonapeptide repeats and secretion by the type I secretion system [13]. Like that of $V$. cholerae, the RTX of $V$. vulnificus has multiple effector domains and can undergo autoprocessing, and therefore is a member of multifunctional autoprocessing RTX (MARTX) family [14]. MARTXs contain two conserved repeated motifs, the GD-rich repeats at $\mathrm{C}$-terminus and the repeats at $\mathrm{N}$-terminus, as well as the effector domains in the central region. It has been demonstrated recently that the $C$ - and N-termini of the MARTX in either $V$. cholerae or $V$. vulnificus are required for toxin secretion and effector translocation $[15,16]$. In addition, deletion of the effector domains of the MARTX in $V$. vulnificus, which causes necrotic death of a variety of eukaryotic cells $[10,12,17,18]$, abolishes the ability to cause rounding, but not lysis, of HeLa cells [16].

The Rho inactivation domain (RID) implicated in causing host cell rounding $[19,20]$ is present in most of the MARTXs of biotype $1 \mathrm{~V}$. vulnificus $[21,22]$. Other domains, like the actin-crosslinking domain (ACD), Pseudomonas aeruginosa ExoY-like adenylate cyclase (ExoY), cysteine protease domain (CPD), alpha-beta hydrolase $(\mathrm{ABH})$, the Makes caterpillars floppy-like (MCF) and Ras/Rap1-specific endopeptidases (RRSPs) domains are found in the MARTXs of $V$. cholerae or $V$. vulnificus [21, 22]. These effector domains have been demonstrated to exert various effects in the host cells [19, 20, 23-28]. The DUF1 (domain of unknown function 1) domain has also been recently shown to interact with prohibitin 1 in HeLa cells to induce cytotoxicity [29]. Although the MARTXs of biotype 1 $\left(\right.$ MARTX $\left._{\mathrm{V}_{\mathrm{v} 1}}\right)$ and biotype $2 \mathrm{~V}$. vulnificus vary in the compositions of effector domains [21], they both promote the survival of this bacterial species in mice during infection by protecting the organism from engulfment by the phagocytes $[10,11]$. However, it is not clear how the MARTX of $V$. vulnificus interferes with ingestion of this microorganism by the phagocytes.

Phagocytosis is an actin-dependent process beginning with engagement of the receptors, like the scavenger receptors, complement receptors, immunoglobulins receptors and toll-like receptors (TLRs), on the phagocyte by bacterial surface components. This causes clustering of the receptors to activate various signaling pathways that lead to actin rearrangement for internalizing the bound bacterium [30]. Actin rearrangement in phagocytosis is known to be regulated by a number of kinases, such as Src family kinases (SFKs) [31], focal adhesion kinase (FAK) [32], proline-rich tyrosine kinase 2 (Pyk2) [32], phosphoinositide 3-kinase (PI3K) [33], Akt [34] and p38 mitogen-activated protein (MAP) kinase [35].

To elucidate the molecular mechanism of the MARTX $_{\mathrm{Vv} 1}$-mediated prevention of bacteria engulfment by the phagocyte, we compared between a wild-type (WT) V. vulnificus strain and its MARTX $_{\mathrm{Vv} 1}$-deficient (MD) mutant for a variety of phagocytosis-related responses they induced in mouse macrophages. We found that in the presence of MARTX $_{\mathrm{Vv} 1}$, the macrophage rounded up and lost the ability to internalize the bacteria shortly after infection due to F-actin disorganization. We further examined whether this was associated with inactivation of the signaling molecules involved in induction of phagocytosis. We also isolated a variety of MARTX $\mathrm{Vv}_{\mathrm{v} 1}$ mutants with deletions in the effector domains to determine the roles of these domains

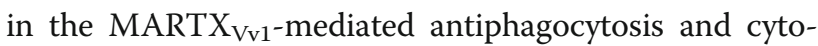
toxicity. Our data suggest that MARTX $\mathrm{Vv}_{\mathrm{V} 1}$ might inhibit phagocytosis by interfering with activation of signaling molecules involved in induction of phagocytosis, a mechanism independent of cell lysis.

\section{Methods \\ Bacterial strains, cells, culture media and reagents}

Strain YJ016, a biotype $1 \mathrm{~V}$. vulnificus clinical isolate, and its MARTX ${ }_{\mathrm{Vv} 1}$-deficient (MD) mutant, HL128 [10], were cultured in LB broth. The mouse peritoneal exudate macrophages (mPEM) was isolated from thioglycollate (Merck)-treated peritoneal cavity of 6 to 8 week-old male BALB/c mice (purchased from the Animal Center of National Cheng Kung University) as described [36]. This experiment was conducted in strict accordance with good animal practice defined in "A guidebook for the care and use of laboratory animals" published by the Council of Agriculture, Executive Yuan in Taiwan. RAW 264.7 cells (mouse macrophage cell line; ATCC TIB7 $^{\mathrm{Ts}}$ ), HeLa cells (human cervical carcinoma cell line; ATCC ${ }^{\circ}$ CCL- $2^{\text {Tu}}$ ) and mPEM were cultured in high glucose Dulbecco's Modified Eagle's Medium (DMEM; Gibco) supplied with $10 \%$ fetal bovine serum (Caisson), $2 \mathrm{mM}$ 
L-glutamine (Gibco) and 1\% penicillin/streptomycin (Caisson). In the bacterium-cell coincubation experiments, the cells were cultured in serum-free high glucose DMEM. PP2 was purchased from Calbiochem. PF431396, LY294002, Akt1/2 kinase inhibitor, cytochalasin $\mathrm{D}$ and dimethyl sulfoxide were purchased from Sigma.

\section{Isolation of the $\triangle v v h A$ and MARTX $\mathrm{V}_{\mathrm{v} 1}$ domain-deletion mutants}

The $\Delta v v h A$ mutant as well as the single, double and triple MARTX $_{\mathrm{Vv} 1}$ domain-deletion mutants, each contains inframe deletion(s) of almost the entire target effector domain in MARTX $_{\mathrm{Vv} 1}$, was isolated by in vivo allelic exchange [37]. The upstream and downstream regions flanking $v v h A$ and the MARTX $\mathrm{Vv}_{\mathrm{v} 1}$ effector domains to be deleted were amplified from $V$. vulnificus YJ016 by PCR with the primer pairs listed in Table 1. The deletions were detected by PCR and confirmed by DNA sequencing.

\section{Phagocytosis assay}

RAW 264.7 cells were coincubated with the bacteria at a multiplicity of infection (MOI) of 10 for $90 \mathrm{~min}$. The internalized bacteria were then envisualized by acridine orange-crystal violet stain as described [38], and observed under an inverted fluorescence microscope (Olympus IX70). Gentamicin protection assay was used to count the internalized bacterial number. Briefly, the extracellular $V$. vulnificus was killed by gentamicin $(100 \mu \mathrm{g} / \mathrm{ml}$, Gibco) for $30 \mathrm{~min}$, and then the intracellular bacteria released from the cells lysed by $0.5 \%$ Triton X100 were enumerated by plate counts.

\section{Cytotoxicity assay}

The cells and bacteria were coincubated at MOI 10, and the cytotoxicity was then estimated by measuring the amount of lactate dehydrogenase (LDH) released from the lysed cells with the CytoTox $96^{\circ}$ Non-Radioactive Cytotoxicity Assay kit (Promega).

\section{Cell rigidity analysis and immunofluorescence microscopy of F-actin}

RAW 264.7 cells and bacteria were coincubated on a $12 \mathrm{~mm}$ cover glass at MOI 10 for $90 \mathrm{~min}$. The rigidity of each of 20-30 selected cells was then examined by atomic force microscopy (AFM; JPK NanoWizard II). Force-distance curves were plotted to quantify the force needed to indent the membrane for a given distance between the AFM tip and cell surface. The elastic (Young's) modulus was calculated from the forcedistance curves by a modified Hertz model (JPK Instruments) built into Elasticity Fit processing software [39]. To examine F-actin, the cells were washed after coincubation with the bacteria, fixed by $1 \%$ formaldehyde, permeablized by $0.5 \%$ triton $\mathrm{X}-100$, stained by Alexa Fluor 488 conjugated phalloidin (Invitrogen), and then observed under a fluorescence microscope (Olympus DP 72).

\section{Anti-MARTX $\mathrm{V}_{\mathrm{V} \mathbf{1} 1}$ antiserum preparation}

The primer pair used to amplify the ERM domain of MARTX $_{\mathrm{Vv} 1}$ (indicated in Fig. 5a) is listed in Table 1. The C-terminal his ${ }_{6}$-tagged ERM peptide produced in E. coli NovaBlue (DE3) was purified by Chelating Sepharose Fast Flow (GE Healthcare), and then used to generate the polyclonal rabbit anti-ERM antiserum (AngeneBiotech, Taipei).

\section{Plasmid DNA transfection}

The plasmid RCAS-myrAkt (Addgene) was introduced into RAW 264.7 cells by transfection using XtremeGENE HP DNA Transfection Reagent (Roche). The cells were subcultured for further analysis after incubation for $48 \mathrm{~h}$ to $72 \mathrm{~h}$.

\section{Immunoblotting}

The proteins in total cell lysate or immunocomplexes were fractionated by $6 \%$ SDS-polyacrylamide gel electrophoresis and then transferred to a PVDF membrane. The membrane was hybridized with primary antibodies (Abs) followed by horse radish peroxidase-conjugated secondary Abs, and the hybridized bands were visualized by enhanced chemiluminescence (PerkinElmer). Densitometric analysis of Akt Pi-S473 was performed with ImageJ software and the results were normalized to total protein level of Akt. The Abs against Pyk2, Pyk2 PiY402, SFKs, PI3K p85 Pi-Y458/p55 Pi-Y199, Akt, Akt PiS473, p38 and p38 Pi-T180/Y182 were purchased from Cell Signaling Technology. Abs against FAK Pi-Y861 and PI3K p85 were purchased from GenScript. Abs against SFKs Pi-Y418, actin and FAK were purchased from Invitrogen, Millipore and BD Biosciences, respectively. Abs against Lyn, Fgr and Hck were purchased from Santa Cruz.

\section{Immunoprecipitation}

One $\mathrm{ml}$ of whole cell lysate (containing 2-5 mg proteins) was pre-cleared by protein G agarose beads (Millipore), and then mixed with $1.5 \mu \mathrm{g}$ of relevant Abs. After incubation at $4{ }^{\circ} \mathrm{C}$ overnight, the immunocomplexes were captured by protein $\mathrm{G}$ agarose beads, washed and denatured by boiling. The proteins in the immunocomplexes were then detected by immunoblotting.

\section{Statistical analyses}

Paired Student's $t$-tests (two-tailed) and one-way analysis of variance (ANOVA) followed by Tukey's test were performed with Prism 5.01 (GraphPad Software). 
Table 1 List of bacterial strains and primers

\begin{tabular}{|c|c|c|c|}
\hline Name & Description $^{a}$ & Note $^{b}$ & Reference/Source \\
\hline \multicolumn{4}{|l|}{ Bacterial strain } \\
\hline YJ016 & wild-type strain & & {$[37]$} \\
\hline HL128 & MARTX $_{V_{V 1} \text {-deficient mutant }}$ & & [10] \\
\hline CJ189 & $\Delta u 1$ mutant & & This study \\
\hline CJ427 & $\Delta r i d$ mutant & & This study \\
\hline CJ338 & $\Delta u 2$ mutant & & This study \\
\hline CJ340 & $\Delta c p d$ mutant & & This study \\
\hline CJ355 & $\Delta g d$ mutant & & This study \\
\hline CJ433 & $\Delta u 1 \Delta r i d$ mutant & & This study \\
\hline CJ190 & $\Delta u 1 \Delta u 2$ mutant & & This study \\
\hline CJ517 & $\Delta$ rid $\Delta u 2$ mutant & & This study \\
\hline CJ429 & $\Delta u 1 \Delta r i d \Delta u 2$ mutant & & This study \\
\hline KV105 & $\Delta v v h A$ mutant & & {$[56]$} \\
\hline KV188 & HL128 $\Delta v v h A$ mutant & & {$[56]$} \\
\hline CJ525 & CJ433 $\Delta v$ vhA mutant & & This study \\
\hline CJ527 & CJ529 $\Delta v v h A$ mutant & & This study \\
\hline \multicolumn{4}{|l|}{ Primer } \\
\hline DU1F1 & 5'-TGTCGACGGGTCACAAAGTC-3' & $\Delta u 1$ & \\
\hline DU1R1 & 5'-AGGATCCAGACGCAGTGGTTGGCAC-3' & $\Delta u 1$ & \\
\hline DU1F2 & 5'-AGGATCCGCCGATACGCTGGTTGAGTTG-3' & $\Delta u 1$ & \\
\hline DU1R2 & 5'-TGAGCTCAGAAAGCCCTGCGAAGATCG-3' & $\Delta u 1$ & \\
\hline SC01 & 5'-AGAGCTCCTGGTTGAGTTGGATGTG-3' & $\Delta r i d$ & \\
\hline SCO2 & 5'-ATCTAGAACTCGGCTTCCAGATGTA-3' & $\Delta r i d$ & \\
\hline SCO3 & 5'-ATCTAGACACACATGGCGACCTAAG-3' & $\Delta r i d$ & \\
\hline SC04 & 5'-AAGCATGCTACCGCTGCTTGCTCTGC-3' & $\Delta r i d$ & \\
\hline DF1 & 5'-TTAGTCGACGTGTTGGACGCCGACAGAG-3' & $\Delta u 2$ & \\
\hline DR1 & 5'-AGGATCCTTCTACCGCTGCTTGCTCTGC-3' & $\Delta u 2$ & \\
\hline DF2f4 & 5'-AGGATCCGTTGTTGTGACTCCGACAGC-3' & $\Delta u 2$ & \\
\hline DR2 & 5'-TGAGCTCCTGCTGCTCTGATCCAAACC-3' & $\Delta u 2$ & \\
\hline SCO7 & 5'-AGAGCTCGGGTTGTTGAGTAAAGCG-3' & $\Delta c p d$ & \\
\hline SC08 & 5'-ATCTAGAGCCACTCAAACTGTCCTT-3' & $\Delta c p d$ & \\
\hline SC09 & 5'-ATCTAGAAACGGTATTGCGGAAGGC-3' & $\Delta c p d$ & \\
\hline SC10 & 5'-AAGCATGCACCCGCTAACTGCCCAAG-3' & $\Delta c p d$ & \\
\hline JL173 & 5'-TATGAGCTCCAACGCACCCTTCGGTTG-3' & $\Delta g d$ & \\
\hline$J L 174$ & 5'-GCGTCTAGATAATATTCACCTTCCATT-3' & $\Delta g d$ & \\
\hline$J L 175$ & 5'-GCGTCTAGACGGCAGGTTAAGCGAGTT-3' & $\Delta g d$ & \\
\hline JL176 & 5'-TATGAGCTCTTGGTTGAACTGGACTCG-3' & $\Delta g d$ & \\
\hline UWA0965F & 5'-AAATGTCGACACCCACATTAA-3' & $\Delta v v h A$ & \\
\hline UWA0965R & 5'-AGAGAAAGCTTAAACAGAGTCAT-3' & $\Delta v v h A$ & \\
\hline DWA0965F & 5'-TCCCAAGCTTCCCACATTACAAC-3' & $\Delta v v h A$ & \\
\hline DWA0965R & 5'-GGAAGAGCTCACCAAACCCG-3' & $\Delta v v h A$ & \\
\hline ERM-1 new & 5'-AACATATGGATCAAACTCAAGCCCCG-3' & ERM & \\
\hline ERM-2 new & 5'-AACTCGAGGGTCCCTITGGCATCATT-3' & ERM & \\
\hline
\end{tabular}

${ }^{\mathrm{a}} u 1$, rid, $u 2, c p d$ and $g d$ correspond to the U1 region, RID domain, U2 region, CPD domain and GD-rich domain, respectively. The underlined sequences in the primers are the restriction sites introduced

${ }^{\mathrm{b}}$ The MARTXVV1 domain-deletion mutant that the primer was used to isolate or the recombinant peptide that the primer was used to clone 


\section{Results}

Effect of MARTX $\mathrm{vv}_{\mathrm{v} 1}$ on morphological change of and actin polymerization in infected macrophages

Infection of the MARTX $\mathrm{V} v 1$-deficient (MD) mutant, HL128, caused formation of stress fibers in the HeLa cells and pseudopodia in the RAW 264.7 cells (Fig. 1a).

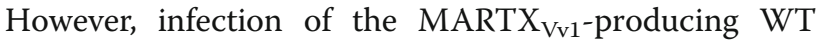
strain resulted in cell rounding of both cell lines and apparent F-actin disorganization in the HeLa cells (Fig. 1a) 90 min after infection. In addition, by AFM we detected reduced rigidity of RAW 264.7 cells 90 min after infection by the WT strain but increased rigidity of those infected by the MD mutant (Fig. 1b). By time-lapse microscopy, we found that RAW 264.7 cells infected by the WT strain, but not MD mutant, lost pseudopodia and rounded up starting from $15 \mathrm{~min}$ after infection (Fig. 2a).

It has been demonstrated that MARTX $\mathrm{V}_{\mathrm{Vv} 1}$ exerts comparable cytotoxicity and antiphagocytosis effect in the RAW 264.7 cells and mouse peritoneal exudate macrophages (mPEM) [10]. We further tested whether mPEM may undergo cell rounding in the presence of

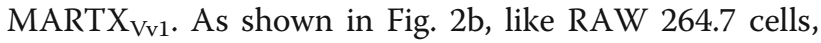
mPEM infected by the WT strain, but not the MD mutant, rounded up starting from $15 \mathrm{~min}$ after infection.

\section{Effect of MARTX $\mathrm{V}_{\mathrm{v} 1}$ on phosphorylation levels of}

\section{phagocytosis-related kinases}

To determine the effect of MARTX $\mathrm{V}_{\mathrm{V} 1}$ on the signaling molecules that regulate actin polymerization, we checked the phosphorylation levels of SFKs, FAK, Pyk2, PI3K, Akt and p38 MAP kinase in RAW 264.7 cells after infection by the WT strain and MD mutant. We found that the WT strain caused dephosphorylation at SFKs Y418, FAK Y861, Pyk2 Y402 and PI3K p85 Y458, but not SFKs Y529 or p38 T180/Y182, $7.5 \mathrm{~min}$ or $15 \mathrm{~min}$ after infection at MOI 10 (Fig. 2c).

Phosphorylation of Akt at Ser473 was detected at 7.5 min after infection by either strain, but it was then dramatically reduced to an undetectable level from 15 min after infection by the WT strain, but not the MD mutant (Fig. 2c). The reduced phosphorylation levels of these proteins in the presence of MARTX $\mathrm{V}_{\mathrm{v} 1}$ were not due to decreased protein expression, because the total amount of each protein was not affected (Fig. 2c). The WT strain also caused dephosphorylation at SFKs Y418, FAK Y861, Pyk2 Y402, PI3K p85 Y458 and Akt S473, but not SFKs Y529 and p38 T180/Y182, in mPEM (Fig. 2d).

As Lyn, Fgr and Hck are known to be the predominant SFKs in macrophages [40, 41], we further determined which of them was dephosphorylated after infection by the WT strain. The protein level of each of them was not significantly affected in the presence of MARTX $\mathrm{V}_{\mathrm{V} 1}$ (Fig. 3a). We then performed immunoprecipitation to determine the phosphorylation level of each protein. In one experiment, precipitation of all SFKs that were phosphorylated at Tyr418 with anti-SFKs Pi-Y418 Ab was followed by immunoblotting with Ab against Lyn,
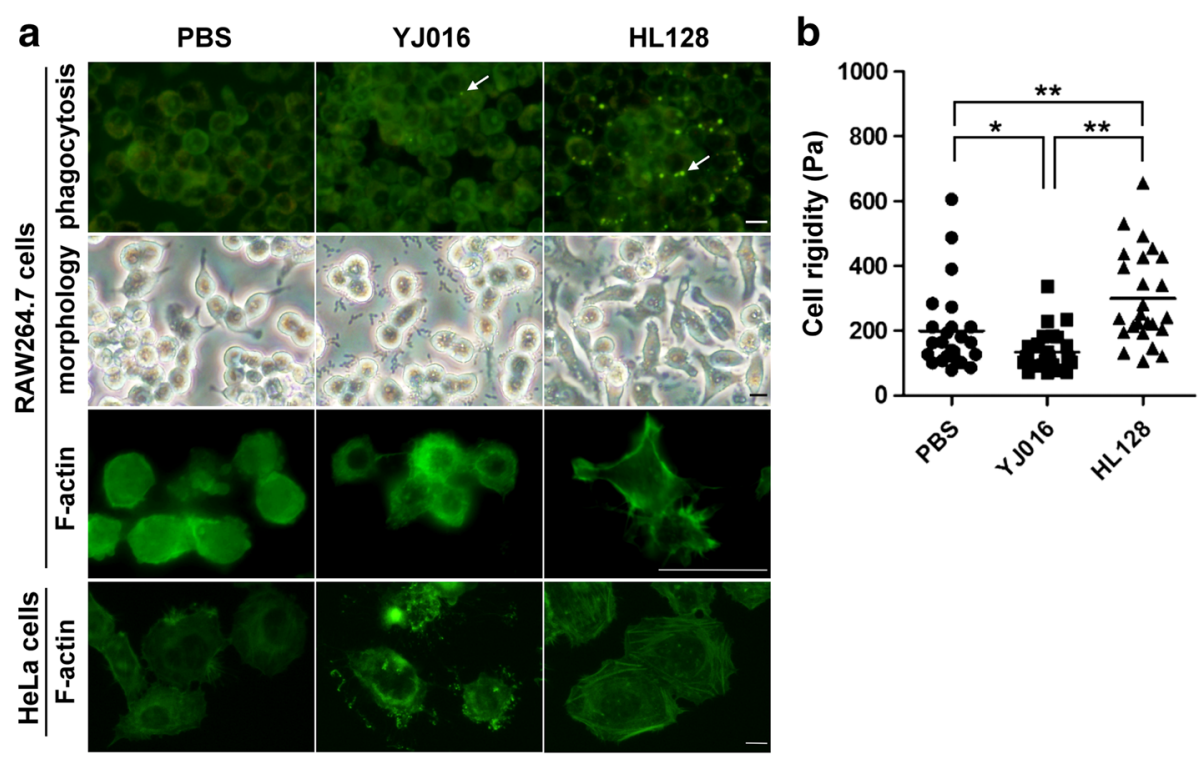

Fig. 1 Morphology, rigidity, F-actin organization and bacteria engulfment of the infected cells. a RAW 264.7 or HeLa cells were coincubated with the WT strain (YJ016) and the MD mutant (HL128) at MOI 10 for 90 min. The morphology of the cells was then examined under a light microscope. The engulfed bacteria (indicated by arrows) were detected under a fluorescence microscope after acridine orange-crystal violet stain. F-actin was stained by Alexa Fluor ${ }^{\circledast} 488$ conjugated phalloidin and observed by fluorescence microscopy. Bar $=20$ um. b Rigidity of RAW 264.7 cells examined by AFM is expressed as Young's Modulus (Pa). * $p<0.05$ and **: $p<0.01$ by paired Student's $t$-tests (two-tailed). $n=3$ 


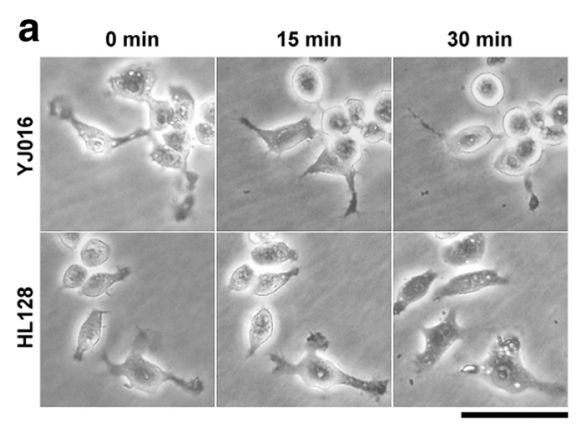

C

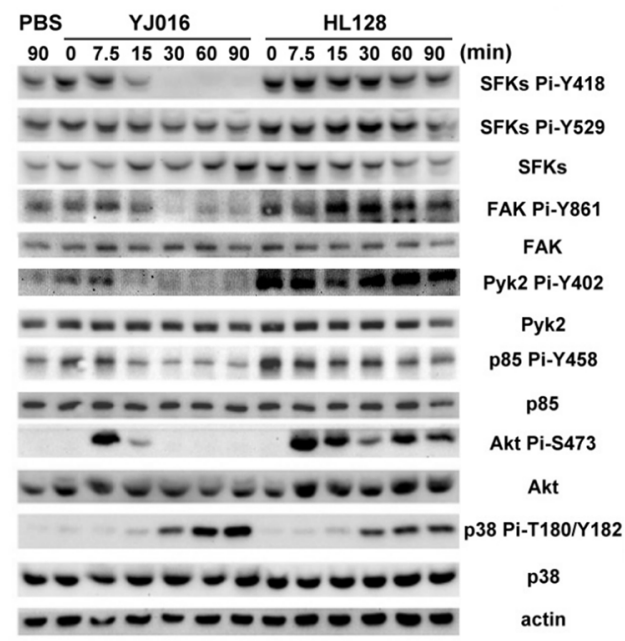

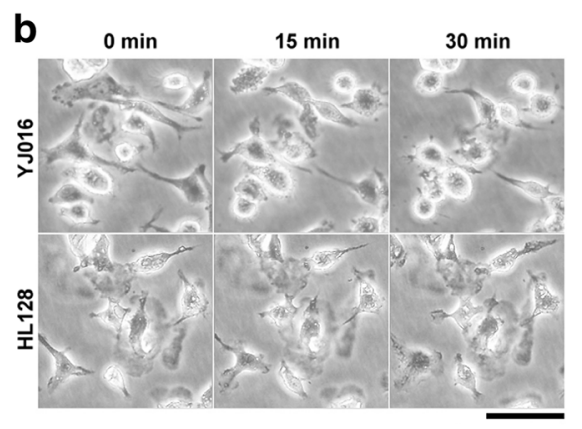

d

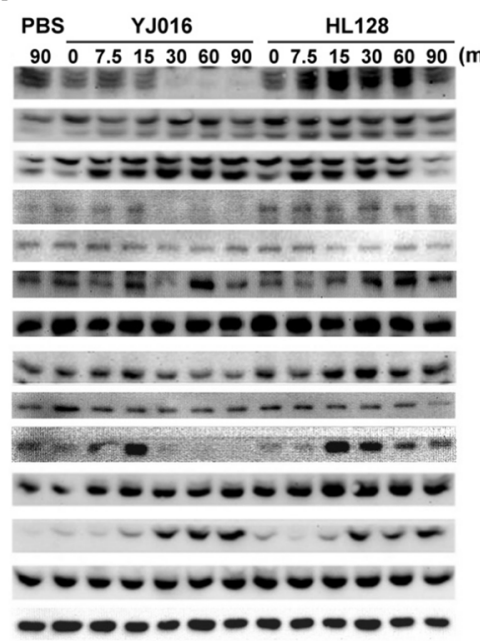

Fig. 2 Morphological change and phosphorylation levels of phagocytosis-related kinases of macrophages after infection by WT strain or MD mutant. RAW 264.7 cells $(\mathbf{a}, \mathbf{b})$ and mPEM (b, d) were coincubated with the WT strain (YJ016) or MD mutant (HL128) at MOI 10 for the indicated periods. a, b The morphological change of infected cells was examined by time-lapse microscopy. Bar $=100 \mu \mathrm{m}$. $\mathbf{c}$, $\mathbf{d}$ The infected cells were lysed, and the total amount and phosphorylation level at the indicated amino acid residue(s) of each kinase were estimated by immunoblotting with relevant antibodies. Data are representative of three independent experiments

Fgr or Hck to detect each protein (Fig. 3b). In another experiment, precipitation of both the phosphorylated and unphosphorylated proteins with anti-Lyn, -Fgr or -Hck Ab was followed by immunoblotting with antiSFKs Pi-Y418 Ab to detect the phosphorylated molecules (Fig. 3c). In either experiment we found that Tyr418 of Lyn, Fgr and Hck were all phosphorylated in the absence of MARTX $_{\mathrm{Vvl}}$, but were all dephosphorylated in the presence of MARTX $_{\mathrm{V}_{\mathrm{v} 1}}$, in RAW 264.7 cells 90 min after infection.

\section{Effects of SFKs, FAK/Pyk2, PI3K and Akt inhibitors on engulfment of MD mutant and phosphorylation of signaling molecules in infected macrophage}

We further used the inhibitors of SFKs, FAK/Pyk2, PI3K and Akt to determine the involvement of these molecules and the relations among them in engulfment of the MD mutant by the macrophage. As shown in Fig. 4a, all of these inhibitors significantly impaired the phagocytosis of MD mutant by RAW 264.7 cells. In addition, the inhibitor of SFKs (PP2) reduced the phosphorylation levels at not only SFKs Y418 but also FAK Y861, Pyk2 Y402 and Akt S473 (Fig. 4b), namely, inactivation of SFKs caused dephosphorylation of FAK, Pyk2 and Akt. The inhibitor of FAK and Pyk2 (PF431396) reduced the phosphorylation levels at FAK Y861, Pyk2 Y402, PI3K p85 Y458 and Akt S473 (the band intensity of Akt Pi-S473 of the treated cells was $68 \%$ of that of the untreated cells), but not SFKs Y418. This shows that inactivation of FAK and Pyk2 can cause dephosphorylation of PI3K and Akt, but not SFKs. The inhibitors of PI3K (LY294002) and Akt (Akt1/2 inhibitor) reduced the phosphorylation level of only Akt S473 (Fig. 4b), indicating that inactivation of PI3K can cause dephosphorylation of Akt, but not SFKs, FAK or Pyk2. More, inactivation of Akt could not cause dephosphorylation of all the other tested kinases. The F-actin inhibitor, cytochalasin D, although significantly inhibited the internalization of MD mutant (Fig. 4a), did not affect the phosphorylation levels of these kinases except for Pyk2 Y402 (Fig. 4b). 


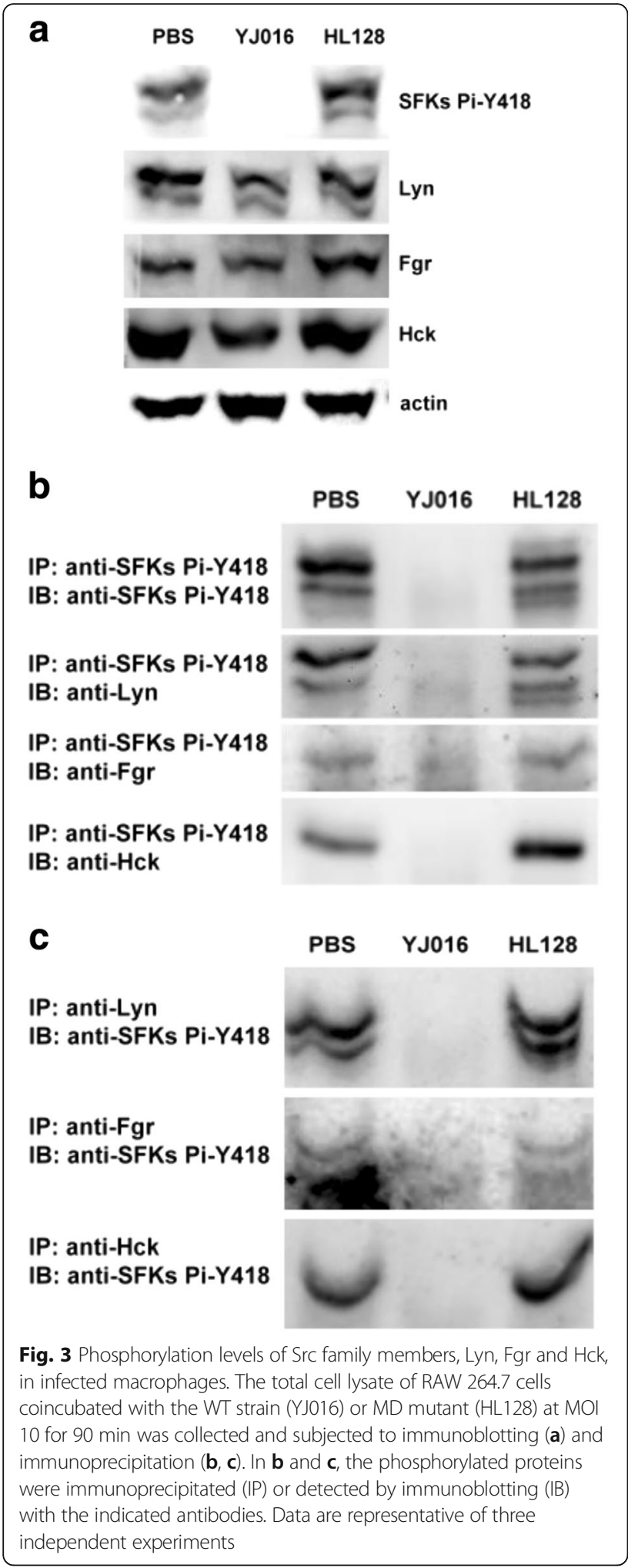

Involvement of MARTX $\mathrm{V}_{\mathrm{v} 1}$ effector domains in cytotoxicity and antiphagocytosis

To determine the roles of various domains of MARTX $_{\mathrm{Vv} 1}$ (Fig. 5a) in antiphagocytosis and lysis of macrophages, we isolated mutants with single, double or triple in-frame deletions of unique sequence 1 (U1, containing DUF1), RID, unique sequence 2 (U2, containing MCF and RRSPs), CPD and GD-rich domain. These mutants all expressed the MARTX $_{\mathrm{Vv} 1}$ mutant proteins (Additional file 1: Figure S1).

Deletion of RID, U2 or CPD domain alone and deletion of both RID and U2 showed wild-type level of cytotoxicity (Fig. 5b) and antiphagocytosis activity (Fig. 5c). Deletion of U1 although resulted in a slight decrease of cytotoxicity to $72.5 \%$ of that of the WT strain, it did not affect the antiphagocytosis activity. In addition, the ability of all of these mutants to cause cell rounding (Fig. 5d) and dephosphorylation of phagocytosis-related kinases in RAW 264.7 cells were not significantly different from that of the WT strain (Fig. 6). On the contrary, deletion of the GD-rich repeats domain eliminated all of these MARTX $_{\mathrm{Vv} 1}$-mediated activities (Fig. 5) and the ability to cause dephosphorylation of the phagocytosisrelated kinases (Fig. 6).

The $\Delta u 1 \Delta$ rid double and $\Delta u 1 \Delta$ rid $\Delta u 2$ triple mutants although exhibited reduced cytotoxicity (Fig. 5b), they caused cell rounding (Fig. 5d) and their antiphagocytosis activity was normal (Fig. 5c). More, the

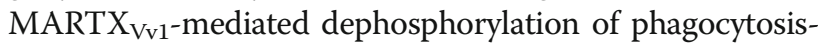
related kinases was abolished in cells infected by these two mutants, except for Akt S473 in the $\Delta u 1 \Delta$ rid mutantinfected and Akt S473 as well as FAK Y861/Pyk Y402 in the $\Delta u 1 \Delta$ rid $\Delta u 2$ mutant-infected cells (Fig. 6). The $\Delta u 1 \Delta u 2$ mutant although resembled the WT strain in cytotoxicity, antiphagocytosis activity and ability to cause cell rounding (Fig. 5b-d), the phosphorylation levels of the phagocytosis-related kinases, except for Akt S473, was not decreased in cells infected by this mutant (Fig. 6).

\section{Effect of myrAkt on phagocytosis of macrophages}

We showed that MARTX $\mathrm{Vv}_{\mathrm{V} 1}$ could cause dephosphorylation of SFKs Y418, FAK Y861, Pyk2 Y402, PI3K p85 Y458 and Akt S473, and inactivation of Akt alone resulted in reduced phagocytosis in RAW 264.7 cells (Fig. 4). In addition, decreased phosphorylation level at Akt S473 correlated well with impaired phagocytosis of RAW 264.7 cells (Fig. 5c and 6). To confirm the role of Akt in phagocytosis of $V$. vulnificus, we tested whether expression of the constitutively active myrAkt [42, 43] in RAW 264.7 cells could result in increased phagocytosis of this organism. As shown in Fig. 7a, phosphorylated myrAkt was expressed in cells with or without infection, while the phosphorylation levels of SFKs, FAK, p85 of PI3K and Akt were not significantly affected. Compared to the normal cells, those expressing myrAkt exhibited significantly increased phagocytosis of the WT strain or MARTX $\mathrm{Vv}_{\mathrm{V} 1}$ domain-deletion mutants, $\Delta u 1 \Delta$ rid and $\Delta u 1 \Delta u 2$, which showed wild-type antiphagocytosis ability (Fig. 7b). 


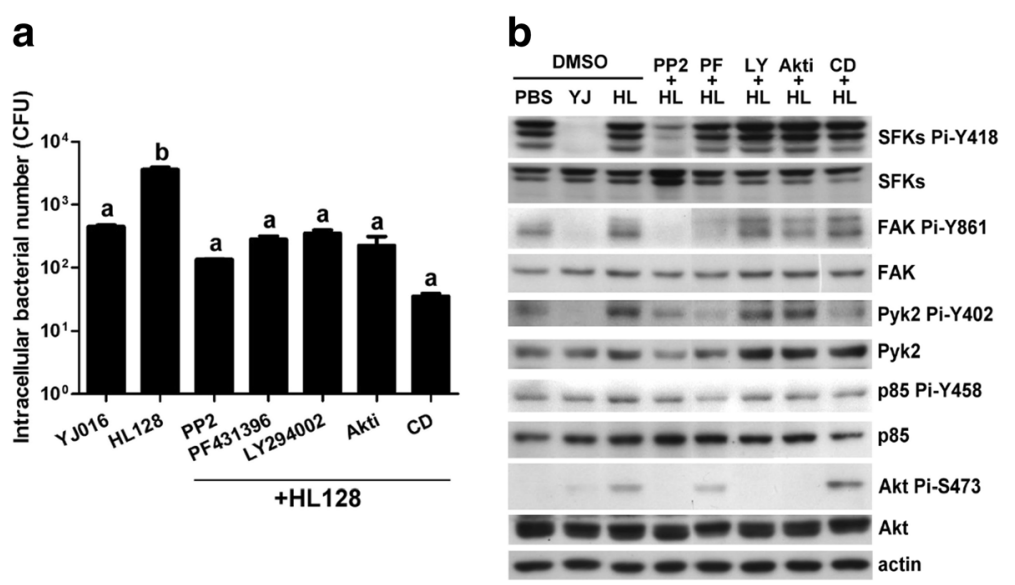

Fig. 4 Effects of specific inhibitors of phagocytosis-related kinases on phagocytosis and phosphorylation of these kinases in infected macrophages. RAW 264.7 cells were pretreated with PP2 (SFKs inhibitor), PF-431396 (Pyk2/FAK inhibitor, PF), LY294002 (PI3K inhibitor, LY), Akt1/2 kinase inhibitor (Akti) and cytochalasin D (F-actin inhibitor, CD) for 4 h, 1 h, 1 h, 1 h and 1 h, respectively. Phagocytosis (a) and the total amount as well as phosphorylation level of each signaling molecule (b) were then estimated by gentamycin protection assay and immunoblotting, respectively, 90 min after coincubation of the pretreated cells with the bacteria at MOI 10. YJ: YJ016, WT strain; HL: HL128, MD mutant. DMSO: 5\% dimethyl sulfoxide, the solvent used as negative control. Data in a were analyzed by one-way ANOVA followed by Tukey's test. $n=3$. Bars labeled with 'a' are not significantly different from each other, but are significantly different from that labeled with ' $b$ ' $(P<0.05)$. Data in $\mathbf{b}$ are representative of three independent experiments

\section{Involvement of effector domains in MARTX $\mathrm{Vv}_{\mathrm{v} 1}$-mediated cytotoxicity and cell rounding in macrophages and epithelial cells}

$V$. vulnificus may encounter different types of cells, including the epithelial cells and phagocytes, during infection. To determine whether the central region of MARTX $_{\mathrm{Vv} 1}$ is similarly involved in the MARTX $\mathrm{Vv1}^{-}$ mediated cytotoxicity and cell rounding in different cell types, we examined the HeLa and RAW 264.7 cells infected by the $\Delta u 1 \Delta$ rid and $\Delta u 1 \Delta$ rid $\Delta u 2 \mathrm{mu}-$ tants for these properties. To avoid the effect of cytolysin, which can cause cell lysis in the bacteria-cell coincubation system at high MOI or after prolonged incubation [17], we deleted its gene, $\nu \nu h A$, from all the tested strains.

The WT strain, but not the MD mutant, caused cytotoxicity of RAW 264.7 cells and HeLa cells 2 h (Fig. 8a) and $3 \mathrm{~h}$ (Fig. $8 \mathrm{~b}$ ), respectively, after infection. The cytotoxicities of $\Delta u 1 \Delta$ rid and $\Delta u 1 \Delta$ rid $\Delta u 2$ mutants to RAW 264.7 cells were much lower than that of the WT strain up to $4 \mathrm{~h}$ post infection (Fig. 8a), while their cytotoxicity to HeLa cells were comparable to the WT strain (Fig. 8b). In addition, the WT strain, but not the MD mutant, caused rounding of both RAW 264.7 and HeLa cells $1 \mathrm{~h}$ after infection (Fig. 8c and d). However, the $\Delta u 1 \Delta$ rid and $\Delta u 1 \Delta$ rid $\Delta u 2$ mutants although caused rounding of RAW 264.7 cells (Fig. 8c), they did not cause rounding of HeLa cells (Fig. 8d), even up to $3.5 \mathrm{~h}$ post infection (data not shown).

We also found that the $\Delta$ rid, $\Delta g d, \Delta u 1 \Delta$ rid , $\Delta$ rid $\Delta u 2$ and $\Delta u 1 \Delta$ rid $\Delta u 2$ mutants, like the MD mutant, did not cause rounding of the HeLa cells 90 min after infection, while the $\Delta u 1, \Delta u 2, \Delta c p d$ and $\Delta u 1 \Delta u 2$ mutants, like the WT strain, caused rounding of these cells (Additional file 2: Figure S2).

\section{Discussion}

MARTX is the major cytotoxin of $V$. vulnificus, and it causes lysis of various mammalian cells, including macrophages and epithelial cells. We have previously demonstrated that the biotype $1 \mathrm{~V}$. vulnificus strain, YJ016, produces MARTX $\mathrm{Vv}_{\mathrm{v} 1}$ to protect itself from engulfment by the macrophage before the phagocyte is lysed by this cytotoxin [10]. In this study, we explored how MARTX $_{\mathrm{Vv1}}$ exerts the antiphagocytosis effect on macrophages by comparing between the macrophages infected by the WT strain and those infected by the MD mutant for a variety of phagocytosis-related properties. We found that the mouse macrophage cell line, RAW 264.7, and mPEM incubated with either the WT strain or MD mutant formed pseudopodia shortly after infection (Fig. 2a and b). But, the WT strain-infected macrophages, which internalized much fewer bacteria (Fig. 1a), began to round up around $15 \mathrm{~min}$ after incubation, while those infected by the MD mutant remained adherent and active (Fig. 2a and b). In addition, the RAW 264.7 cells became more rigid after infection by the MD mutant, but they became less rigid, suggesting F-actin depolymerization as proposed previously [44], after infection by the WT strain (Fig. 1b). HeLa cells exhibited morphological change similar to that of RAW 264.7 cells after infection by either strain. Nevertheless, the stress 


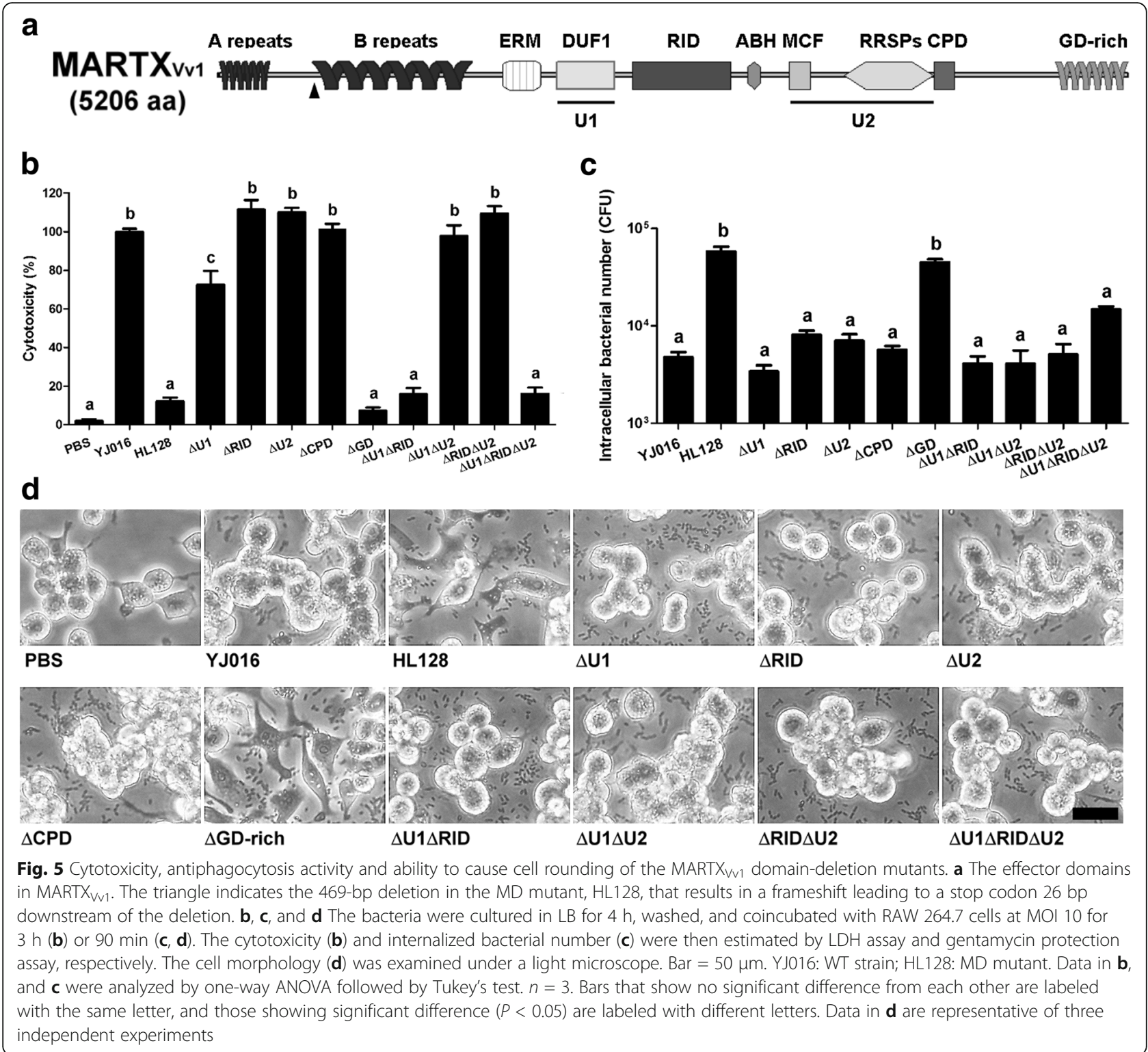

fibers, which were disintegrated and became aggregates in the rounded cells $90 \mathrm{~min}$ after infection by the WT strain, were clearly observed in HeLa cells, but not RAW 264.7 cells (Fig. 1a). These suggest that MARTX $_{\mathrm{Vv} 1}$ might inhibit cytoskeleton rearrangement in the macrophage to result in cell rounding and inability to internalize the infecting bacteria.

Actin rearrangement in macrophage during phagocytosis is regulated by a number of signaling molecules, which are activated in a cascade by phosphorylation at specific amino acid residues [32, 34, 35, 45-47] when the signal is triggered upon bacterium-macrophage interaction. In both the RAW 264.7 cells and MPEM, infection by the WT strain, but not MD mutant, resulted in dephosphorylation at SFKs Y418, FAK Y861, Pyk2
Y402, PI3K p85 Y458 and Akt S473 (Fig. 2c and d). This suggests that MARTX $\mathrm{V}_{\mathrm{V} 1}$ might interfere with phagocytosis by inactivating these kinases. The p38 MAP kinase has been shown to be involved in the TLRs-MyD88 pathway-mediated phagocytosis of interacting bacteria [35]. Nevertheless, antiphagocytosis mediated by MARTX $_{\mathrm{Vv} 1}$ may not be via inactivating this TLRdependent signaling pathway, because T180/Y182 of p38 was phosphorylated upon infection despite the presence of MARTX $_{\mathrm{Vv1}}$ (Fig. 2c and d).

MARTX $_{\mathrm{Vv} 1}$ caused dephosphorylation of all the predominant SFKs, i.e. Lyn, Fgr and Hck, in RAW 264.7 cells (Fig. 3). These SFK members have been shown to be associated with different receptors residing in the lipid raft [48], a specific plasma membrane platform for 


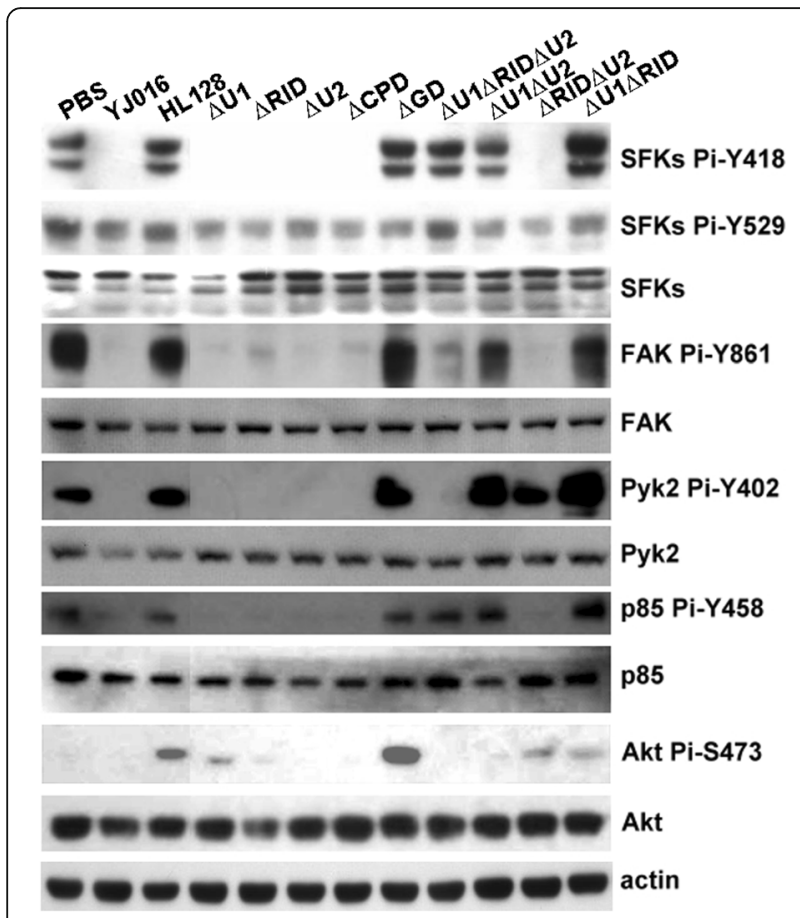

Fig. 6 Phosphorylation levels of phagocytosis-related kinases in macrophages infected by MARTX $X_{V 1}$ domain-deletion mutants. The bacteria were cultured in LB for $4 \mathrm{~h}$, washed, and coincubated with RAW 264.7 cells at MOI 10 for 90 min. Total cell lysate of the infected RAW 264.7 cells was collected, and the phosphorylation level of each kinase was examined by immunoblotting. YJ016: WT strain; HL128: MD mutant. Data are representative of three independent experiments organizing the receptors and their downstream molecules to initiate signaling pathways [49]. The possibility that MARTX $_{\mathrm{Vv} 1}$ may cause dephosphorylation of SFKs by disrupting the lipid rafts was excluded as this structure remained intact up to 90 min after infection by the WT strain (our unpublished data). Dephosphorylation at Y418 of SFKs might not due to a negative feedback on the autokinase activity resulting from increased phosphorylation at Tyr529 of SFKs [45], as phosphorylation of Tyr529 was in fact slightly reduced in cells infected by the WT strain (Fig. 2c and d). Whether phosphatases may be involved in dephosphorylation of SFKs awaits further investigation.

By using the kinase inhibitors of SFKs, FAK/Pyk2, PI3K and Akt, we further demonstrated that these kinases were all involved in phagocytosis of the MD mutant (Fig. 4a). In addition, from the effect of each inhibitor on the phosphorylation levels of these molecules (Fig. 4b), a signaling pathway, SFKs-FAK/Pyk2PI3K-Akt, can be depicted. The order of these molecules in this signaling pathway is supported by other studies, which showed that FAK and Pyk2 were phosphorylated by the activated SFKs [50-52]; PI3K was downstream of FAK [53] and Pyk2 [51]; and Akt was activated by the phosphorylated PI3K [54]. Like treatment with the SFKs inhibitor, PP2, infection by the WT strain resulted in dephosphorylation of these molecules, suggesting that MARTX $_{\mathrm{Vv} 1}$ might cause inactivation of this signaling pathway to impair bacteria engulfment.

There are several putative effector domains in the central region of MARTX $\mathrm{V}_{\mathrm{v} 1}$, and some of them share high

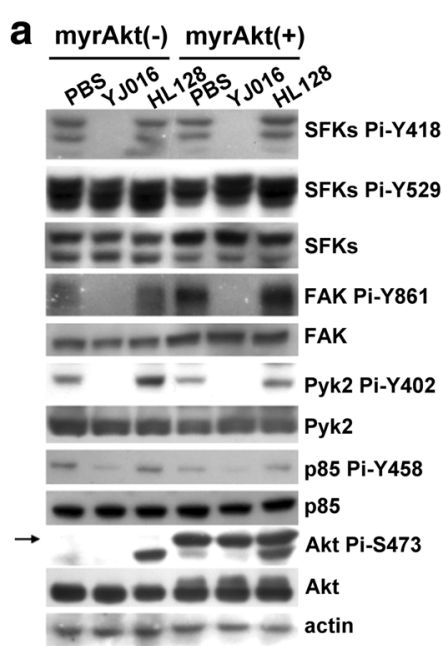

b

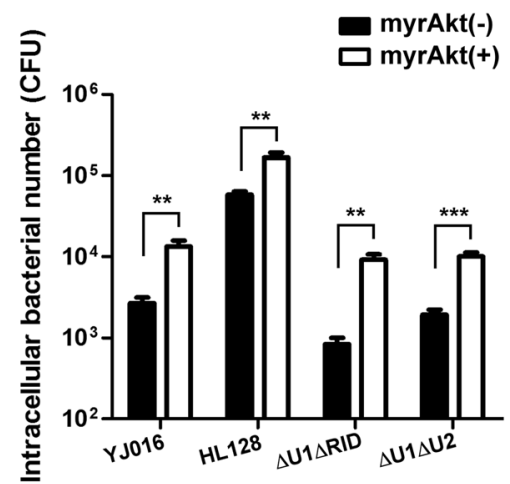

Fig. 7 Effects of myrAkt on phagocytosis and phosphorylation levels of phagocytosis-related kinases in macrophages. The normal (myr-Akt(-)) and myrAkt-expressing (myr-Akt(+)) RAW 264.7 cells were coincubated with the washed bacteria at MOI 10 for 90 min. The total amount and phosphorylation level at the indicated amino acid residue(s) of each kinase (a) as well as the internalized bacteria number (b) were then estimated by immunoblotting and gentamycin protection assay, respectively. The band of myrAkt is indicated by an arrow. YJ016: WT strain; HL128: MD mutant. **: $P<0.01 ; * *: P<0.001$ by paired Student's $t$-tests (two-tailed). $n=3$. Data in a are representative of three independent experiments 

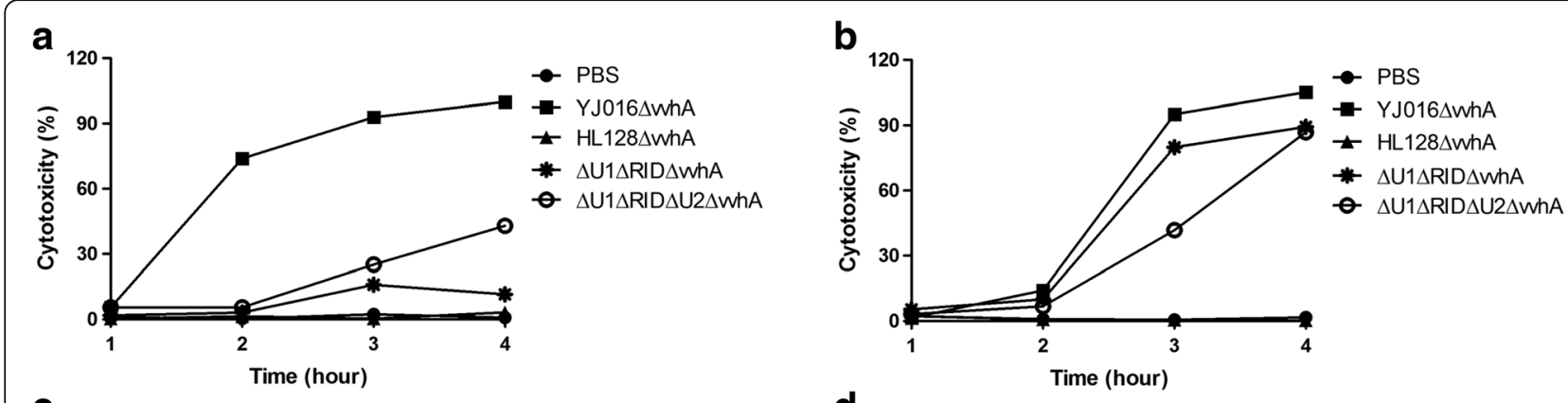

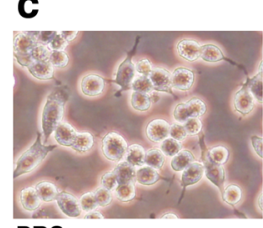

PBS

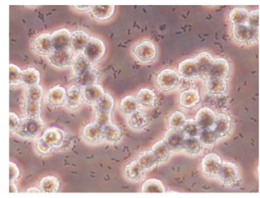

$\Delta \mathrm{U} 1 \Delta \mathrm{RID} \Delta v \boldsymbol{v} h A$

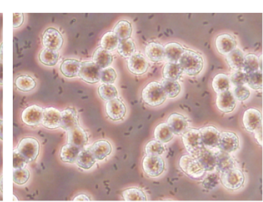

YJ016 $\Delta v V h A$

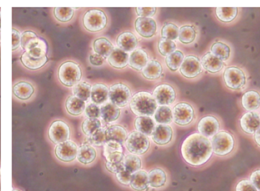

$\Delta \mathrm{U} 1 \Delta \mathrm{RID} \Delta \mathrm{U} 2 \Delta v v h A$

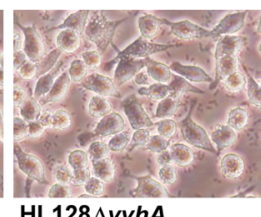

HL128 $\Delta v v h A$

Fig. 8 MARTXVV1-mediated cytotoxicity and morphological change in macrophage and epithelial cell lines. The bacteria were cultured in LB for 4 h, washed, and coincubated with RAW 264.7 cells $(\mathbf{a}, \mathbf{c})$ or HeLa cells $(\mathbf{b}, \mathbf{d})$ at $\mathrm{MOI} 10$ for the indicated periods (a, b) or $1 \mathrm{~h}(\mathbf{c}, \mathbf{d})$. The cytotoxicity $(\mathbf{a}, \mathbf{b})$ was estimated by LDH assay $(n=3)$, and the cell morphology $(\mathbf{c}$, $\mathbf{d})$ was examined under a light microscope. YJ016: WT strain; HL128: MD mutant. Data in $\mathbf{c}$ and $\mathbf{d}$ are representative of three independent experiments

similarity to their equivalents in the MARTX of $V$. cholerae. By characterizing a set of MARTX $_{\mathrm{Vv} 1}$ effector domain-deletion mutants, we showed that domains DUF1, RID and CPD as well as the U2 region that contains MCF and RRSPs were individually dispensable for the MARTX $\mathrm{Vv}_{\mathrm{V} 1}$-mediated cytotoxicity, cell rounding, antiphagocytosis and dephosphorylation of the phagocytosisrelated kinases in the macrophage (Fig. 5b-5d, Fig. 6). On the contrary, deletion of the GD-rich repeats domain abolished these effects of MARTX $\mathrm{Vv}_{\mathrm{v} 1}$ (Fig. 5b-5d, Fig. 6) as was expected based on the crucial role of this domain in secretion of this toxin [13].

Interestingly, $\Delta u 1 \Delta$ rid and $\Delta u 1 \Delta \operatorname{rid} \Delta u 2$, showed markedly reduced cytotoxicity but exhibited wild-type antiphagocytosis activity and caused cell rounding (Fig. 5b-5d). This is different from the results of a study conducted with the epithelial cell line, HeLa cells. In that study, Kim et al. found that the effector domains-containing central region of MARTX $_{\mathrm{V}_{\mathrm{v} 1}}$ was associated with the ability to cause cell rounding, but not cell lysis [16]. Here we show that the $\Delta u 1 \Delta$ rid and $\Delta u 1 \Delta$ rid $\Delta u 2$ mutants displayed wild-type cytotoxicity to HeLa cells but, unlike the WT strain, they did not cause rounding of these cells (Fig. 8b and d). However, in RAW 264.7 cells these two mutants although exhibited low cytotoxicity, they caused cell rounding (Fig. 8a and c). These indicate that the epithelial cell and macrophage responded differently to these two MARTX $\mathrm{Vv}_{\mathrm{v} 1}$ mutant proteins, with the former being more readily lysed and the later more easily rounding up. We confirmed that RID, which inactivates Rho, $\mathrm{Rac}$ and $\mathrm{Cdc} 42$ to result in actin depolymerization [19], is required for rounding of the epithelial cells mediated by MARTX $\mathrm{Vv}_{\mathrm{V} 1}$, since all and only the mutants with deletion of RID lost the ability to cause rounding of HeLa cells (Additional file 2: Figure S2). However, deletion of the majority part of central region in the $\Delta u 1 \Delta$ rid $\Delta u 2$ mutant did not result in loss of the ability to cause cell rounding and inhibit phagocytosis of RAW 264.7 cells (Fig. 5c and d). The N-and C-termini of this toxin, instead, might be responsible for causing cell rounding and inhibition of phagocytosis in the macrophage by a mechanism that awaits further exploration. It is not clear at the moment why these two types of cell responded differently to the MARTX $\mathrm{Vv}_{\mathrm{V} 1}$ domain-deletion mutants.

The defect of the $\Delta u 1 \Delta$ rid and $\Delta u 1 \Delta$ rid $\Delta u 2$ mutants in cytotoxicity to RAW 264.7 cells may result from reduced amount and/or activity of these MARTX $\mathrm{Vv}_{\mathrm{v} 1} \mathrm{mu}$ tant proteins interacting with the cells, which remains to be determined. In addition, as these two mutants were defective in cytotoxicity, but not antiphagocytosis, it suggests that MARTX $\mathrm{Vv1}_{\mathrm{V}}$ may execute cytotoxicity and antiphagocytosis by different mechanisms. 
Our data clearly indicate that the ability of the WT strain and MARTX $\mathrm{V}_{\mathrm{V} 1}$ domain-deletion mutants to inhibit phagocytosis correlated with their ability to cause rounding of the macrophage. Intriguingly, the $\Delta u 1 \Delta$ rid, $\Delta u 1 \Delta u 2$ and $\Delta u 1 \Delta$ rid $\Delta u 2$ mutants although retained the antiphgocytosis activity and ability to cause cell rounding (Fig. 5c and d), they did not cause dephosphorylation of the tested kinases, except Akt for the $\Delta u 1 \Delta$ rid and $\Delta u 1 \Delta u 2$ mutants and FAK/Pyk2, in addition, for the $\Delta u 1 \Delta$ rid $\Delta u 2$ mutant (Fig. 6). The $\Delta u 1 \Delta$ rid $\Delta u 2$ mutant, which resulted in complete dephosphorylation of Akt, showed slightly lower antiphagocytosis activity (without statistically significant difference) compared to the $\Delta u 1$ mutant, which resulted in partial dephosphorylation of Akt (Fig. 5c and 6). This could be because the $\Delta u 1 \Delta$ rid $\Delta u 2$ mutant was less functional than the $\Delta u 1$ mutant due to a larger deletion region in MARTX $\mathrm{Vv}_{\mathrm{v} 1}$. We further found that engulfment of the WT strain as well as the $\Delta u 1 \Delta$ rid and $\Delta u 1 \Delta u 2$ mutants was increased significantly in RAW 264.7 cells that expressed the constitutively active Akt, myr-Akt (Fig. 7). Collectively, our data suggest that a reduced phosphorylation level at Akt S473 might be responsible for inhibition of phagocytosis by MARTX $\mathrm{Vv}_{\mathrm{v} 1}$, which is plausible as Akt has been shown to physically interact with the actin filament [55]. Nevertheless, engulfment of the WT strain or the $\Delta u 1 \Delta$ rid and $\Delta u 1 \Delta u 2$ mutants was not restored to the level of MD mutant-infected cells in the presence of myr-Akt, implying that there may be other MARTX $\mathrm{V}_{\mathrm{v} 1^{-}}$mediated antiphagocytosis mechanisms. Alternatively, myr-Akt, although is phosphorylated, may not be as active as the phosphorylated endogenous Akt. Akt may not inhibit phagocytosis by directly inactivating actin polymerization, because inhibition of actin polymerization by cytochalasin $\mathrm{D}$ did not affect the phosphorylation levels of these signaling molecules (Fig. 4b).

\section{Conclusions}

Our data show that MARTX $_{\mathrm{Vv} 1}$ of $V$. vulnificus causes inactivation of the phagocytosis-related SFKs-FAK/Pyk2PI3K-Akt signaling pathway, which could lead to cell rounding and impaired phagocytosis of the infected macrophage. In addition, the majority of the central region, which consists of the effector domains, of MARTX $_{\mathrm{Vv} 1}$ is not associated with the antiphagocytosis activity.

\section{Additional files}

Additional file 1: Figure S1. Expression of $M_{A R T X_{V} 1}$ mutant proteins in the domain-deletion mutants. Total cell lysate collected from the bacteria cultured in LB for $4 \mathrm{~h}$ was fractionated by electrophoresis on an $8 \%$ SDS-polyacrylamide gel and then subjected to immunoblotting with anti-ERM antibody. YJ016: WT strain; HL128: MD mutant. Data are representative of three independent experiments. (TIFF $989 \mathrm{~kb}$ )
Additional file 2: Figure S2. Morphological change of HeLa cells infected by various MARTX $\mathrm{V}_{\mathrm{v} 1}$ domain-deletion mutants. Morphology of the HeLa cells coincubated with bacteria at MOI 10 for 90 min was examined under a light microscope. YJ016: WT strain; HL128: MD mutant. Bar $=50 \mu \mathrm{m}$. Data are representative of three independent experiments. (TIFF $3870 \mathrm{~kb}$ )

\section{Abbreviations}

Ab: Antibody; LB medium: Luria-Bertani medium; MOI: Multiplicity of infection; PCR: Polymerase chain reaction

\section{Acknowledgements}

We thank Jing-Jung Wu, Ching-Hao Teng, Yi-Chi Lai and Meng-Ru Shen for their critical suggestions. We also thank Yen-Jen Chen, Huan-Ching Lin, Yu-Ping Lin, Sheng-Yi Chen, Jyun-Yuan Huang, Yen-Jen Chen and Ying-Ting Chen for their valuable technical assistance.

\section{Funding}

This study was supported by the Ministry of Science and Technology, Taiwan (NSC 100-2320-B-006-012-MY3).

\section{Availability of data and materials}

All data and materials are available.

\section{Authors' contributions}

CLC performed major experiments, data analysis, and wrote the paper. SCC, $\mathrm{HIH}, \mathrm{THL}$ and MJT performed a part of experiments and data analysis. $\mathrm{LIH}$ designed the research and wrote the paper. All authors read and approved the final manuscript.

\section{Ethics approval}

All the animal experiments conducted in this study used the mice purchased from the animal center of College of Medicine in NCKU. The protocol of animal experiments was reviewed and approved by the Animal Ethics Committee of NCKU (Reference no. 100142).

\section{Consent for publication}

Not applicable.

\section{Competing interests}

The authors declare that they have no competing interests.

\section{Publisher's Note}

Springer Nature remains neutral with regard to jurisdictional claims in published maps and institutional affiliations.

\section{Author details}

'Department of Microbiology and Immunology, College of Medicine, National Cheng Kung University, Tainan 70101, Taiwan. ${ }^{2}$ Institute of Basic Medical Sciences, College of Medicine, National Cheng Kung University, Tainan 70101, Taiwan. ${ }^{3}$ Department of Pharmacology College of Medicine, National Cheng Kung University, Tainan 70101, Taiwan. ${ }^{4}$ Department of Physiology, College of Medicine, National Cheng Kung University, Tainan 70101, Taiwan.

Received: 25 April 2017 Accepted: 13 August 2017

Published online: 19 August 2017

\section{References}

1. Bisharat N, Agmon V, Finkelstein R, Raz R, Ben-Dror G, Lerner L, Soboh S, Colodner R, Cameron DN, Wykstra DL, et al. Clinical, epidemiological, and microbiological features of Vibrio vulnificus biogroup 3 causing outbreaks of wound infection and bacteraemia in Israel. Israel Vibrio Study Group Lancet. 1999:354:1421-4.

2. Tison DL, Nishibuchi M, Greenwood JD, Seidler RJ. Vibrio vulnificus biogroup 2: new biogroup pathogenic for eels. Appl Environ Microbiol. 1982;44:640-6.

3. Jones MK, Oliver JD. Vibrio vulnificus: disease and pathogenesis. Infect Immun. 2009;77:1723-33.

4. Yoshida S, Ogawa M, Mizuguchi Y. Relation of capsular materials and colony opacity to virulence of Vibrio vulnificus. Infect Immun. 1985;47:446-51. 
5. Litwin CM, Rayback TW, Skinner J. Role of catechol siderophore synthesis in Vibrio vulnificus virulence. Infect Immun. 1996;64:2834-8.

6. Webster AC, Litwin CM. Cloning and characterization of vuuA, a gene encoding the Vibrio vulnificus ferric vulnibactin receptor. Infect Immun. 2000;68:526-34

7. Lee JH, Rho JB, Park KJ, Kim CB, Han YS, Choi SH, Lee KH, Park SJ. Role of flagellum and motility in pathogenesis of Vibrio vulnificus. Infect Immun. 2004;72:4905-10.

8. Paranjpye RN, Strom MS. A Vibrio vulnificus type IV pilin contributes to biofilm formation, adherence to epithelial cells, and virulence. Infect Immun. 2005;73:1411-22.

9. Kim IH, Kim IJ, Wen Y, Park NY, Park J, Lee KW, Koh A, Lee JH, Koo SH, Kim KS. Vibrio vulnificus secretes an insulin-degrading enzyme that promotes bacterial proliferation in vivo. J Biol Chem. 2015;290:18708-20

10. Lo HR, Lin JH, Chen YH, Chen CL, Shao CP, Lai YC, Hor LI. RTX toxin enhances the survival of Vibrio vulnificus during infection by protecting the organism from phagocytosis. J Infect Dis. 2011;203:1866-74.

11. Lee CT, Pajuelo D, Llorens A, Chen YH, Leiro JM, Padros F, Hor LI, Amaro C. MARTX of Vibrio vulnificus biotype 2 is a virulence and survival factor. Environ Microbiol. 2013;15:419-32.

12. Lee JH, Kim MW, Kim BS, Kim SM, Lee BC, Kim TS, Choi SH. Identification and characterization of the Vibrio vulnificus rtxA essential for cytotoxicity in vitro and virulence in mice. J Microbiol. 2007:45:146-52.

13. Linhartová I, Bumba L, Mašn J, Basler M, Osička R, Kamanová J, Procházková K, Adkins I, HejnováHolubová J, Sadílková L, et al. RTX proteins: a highly diverse family secreted by a common mechanism. FEMS Microbiol Rev. 2010;34:1076-112.

14. Satchell KJ. MARTX, multifunctional autoprocessing repeats-in-toxin toxins. Infect Immun. 2007;75:5079-84.

15. Dolores JS, Agarwal S, Egerer M, Satchell KJ. Vibrio cholerae MARTX toxin heterologous translocation of beta-lactamase and roles of individual effector domains on cytoskeleton dynamics. Mol Microbiol. 2015;95:590-604.

16. Kim BS, Gavin HE, Satchell KJ. Distinct roles of the repeat-containing regions and effector domains of the Vibrio vulnificus multifunctional-autoprocessing repeats-in-toxin (MARTX) toxin. mBio 2015;6:e00324-15.

17. Kim YR, Lee SE, Kook H, Yeom JA, Na HS, Kim SY, Chung SS, Choy HE, Rhee JH. Vibrio vulnificus RTX toxin kills host cells only after contact of the bacteria with host cells. Cell Microbiol. 2008;10:848-62.

18. Liu M, Alice AF, Naka $\mathrm{H}, \mathrm{Crosa} \mathrm{JH}$. The HlyU protein is a positive regulator of rtxA1, a gene responsible for cytotoxicity and virulence in the human pathogen Vibrio vulnificus. Infect Immun. 2007;75:3282-9.

19. Sheahan $\mathrm{KL}$, Satchell KJ. Inactivation of small rho GTPases by the multifunctional RTX toxin from Vibrio cholerae. Cell Microbiol. 2007;9:1324-35.

20. Gavin HE, Beubier NT, Satchell KJ. The effector domain region of the Vibrio vulnificus MARTX toxin confers biphasic epithelial barrier disruption and is essential for systemic spread from the intestine. PLoS Pathog. 2017:13:e1006119.

21. Roig FJ, Gonzalez-Candelas F, Amaro C. Domain organization and evolution of multifunctional autoprocessing repeats-in-toxin (MARTX) toxin in Vibrio vulnificus. Appl Environ Microbiol. 2011;77:657-68.

22. Kwak JS, Jeong HG, Satchell KJ. Vibrio vulnificus rtxA1 gene recombination generates toxin variants with altered potency during intestinal infection. Proc Natl Acad Sci U S A. 2011;108:1645-50

23. Sheahan $\mathrm{KL}$, Cordero $\mathrm{CL}$, Satchell $\mathrm{KJ}$. Identification of a domain within the multifunctional Vibrio cholerae RTX toxin that covalently cross-links actin. Proc Natl Acad Sci U S A. 2004;101:9798-803.

24. Sheahan KL, Cordero CL, Satchell KJ. Autoprocessing of the Vibrio cholerae RTX toxin by the cysteine protease domain. EMBO J. 2007;26:2552-61.

25. Ziolo KJ, Jeong HG, Kwak JS, Yang S, Lavker RM, Satchell KJ. Vibrio vulnificus biotype 3 multifunctional autoprocessing RTX toxin is an adenylate cyclase toxin essential for virulence in mice. Infect Immun. 2014;82:2148-57.

26. Antic I, Biancucci M, Zhu Y, Gius DR, Satchell KJ. Site-specific processing of Ras and Rap1 switch I by a MARTX toxin effector domain. Nat Commun. 2015:6:7396.

27. Agarwal S, Kim H, Chan RB, Agarwal S, Williamson R, Cho W, Paolo GD, Satchell KJ. Autophagy and endosomal trafficking inhibition by Vibrio cholerae MARTX toxin phosphatidylinositol-3-phosphate-specific phospholipase A1 activity. Nat Commun. 2015;6:8745.

28. Agarwal S, Agarwal S, Biancucci M, Satchell KJ. Induced autoprocessing of the cytopathic makes caterpillars floppy-like effector domain of the Vibrio vulnificus MARTX toxin. Cell Microbiol. 2015;17:1494-509.
29. Kim BA, Lim JY, Rhee JH, Kim YR. Characterization of prohibitin 1 as a host partner of Vibrio vulnificus RtxA1 toxin. J Infect Dis. 2016;213:131-8.

30. Stuart LM, Ezekowitz RA. Phagocytosis and comparative innate immunity: learning on the fly. Nat Rev Immunol. 2008:8:131-41.

31. Berton G, Mocsai A, Lowell CA. Src and Syk kinases: key regulators of phagocytic cell activation. Trends Immunol. 2005;26:208-14.

32. Bruce-Staskal PJ, Weidow CL, Gibson JJ, Bouton AH. Cas, Fak and Pyk2 function in diverse signaling cascades to promote Yersinia uptake. J Cell Sci. 2002;115:2689-700.

33. Marshall JG, Booth JW, Stambolic V, Mak T, Balla T, Schreiber AD, Meyer T, Grinstein S. Restricted accumulation of phosphatidylinositol 3-kinase products in a plasmalemmal subdomain during Fcg receptor-mediated phagocytosis. J Cell Biol. 2001;153:1369-80.

34. Forsberg M, Blomgran R, Lerm M, Sarndahl E, Sebti SM, Hamilton A, Stendahl O, Zheng L. Differential effects of invasion by and phagocytosis of Salmonella typhimurium on apoptosis in human macrophages: potential role of rho-GTPases and Akt. J Leukoc Biol. 2003:74:620-9.

35. Kong L, Ge BX. MyD88-independent activation of a novel actin-Cdc42/Rac pathway is required for toll-like receptor-stimulated phagocytosis. Cell Res. 2008;18:745-55.

36. Zhang X, Goncalves R, Mosser DM. The isolation and characterization of murine macrophages. Curr Protoc Immunol. 2008; Chapter 14:Unit 14.1.

37. Fan JJ, Shao CP, Ho YC, Yu CK, Hor LI. Isolation and characterization of a Vibrio vulnificus mutant deficient in both extracellular metalloprotease and cytolysin. Infect Immun. 2001;69:5943-8.

38. Miliotis MD. Acridine orange stain for determining intracellular enteropathogens in HeLa cells. J Clin Microbiol. 1991:29:830-1.

39. Chen JY, Tsai PJ, Tai HC, Tsai RL, Chang YT, Wang MC, Chiou YW, Yeh ML, Tang MJ, Lam CF, et al. Increased aortic stiffness and attenuated lysyl oxidase activity in obesity. Arterioscler Thromb Vasc Biol. 2013;33:839-46.

40. Baruzzi A, Caveggion E, Berton G. Regulation of phagocyte migration and recruitment by Src-family kinases. Cell Mol Life Sci. 2008;65:2175-90.

41. Lowell CA. Src-family kinases: rheostats of immune cell signaling. Mol Immun. 2004;41:631-43.

42. Andjelkovic $M$, Alessi DR, Meier R, Fernandez $A$, Lamb NJ, Frech $M$, Cron $P$, Cohen P, Lucocq JM, Hemmings BA. Role of translocation in the activation and function of protein kinase B. J Biol Chem. 1997;272:31515-24.

43. Maurer-Stroh S, Eisenhaber B, Eisenhaber F. N-terminal N-myristoylation of proteins: refinement of the sequence motif and its taxon-specific differences. J Mol Biol. 2002;317:523-40.

44. Callies C, Fels J, Liashkovich I, Kliche K, Jeggle P, Kusche-Vihrog K, Oberleithner H. Membrane potential depolarization decreases the stiffness of vascular endothelial cells. J Cell Sci. 2011;124:1936-42.

45. Roskoski R Jr. Src kinase regulation by phosphorylation and dephosphorylation Biochem Biophys Res Commun. 2005;331:1-14.

46. Tabassam FH, Graham DY, Yamaoka Y. OipA plays a role in Helicobacter pylori-induced focal adhesion kinase activation and cytoskeletal reorganization. Cell Microbiol. 2008;10:1008-20.

47. Devarajan A, Bourquard N, Grijalva VR, Gao F, Ganapathy E, Verma J, Reddy ST. Role of PON2 in innate immune response in an acute infection model. Mol Genet Metab. 2013;110:362-70.

48. Korade-Mirnics Z, Corey SJ. Src kinase-mediated signaling in leukocytes. J Leukoc Biol. 2000;68:603-13.

49. Simons K, Toomre D. Lipid rafts and signal transduction. Nat Rev Mol Cell Biol. 2000;1:31-9

50. Calalb MB, Zhang $X$, Polte TR, Hanks SK. Focal adhesion kinase tyrosine-861 is a major site of phosphorylation by Src. Biochem Biophys Res Commun. 1996:228:662-8

51. Cipolla L, Consonni A, Guidetti G, Canobbio I, Okigaki M, Falasca M, Ciraolo E, Hirsch E, Balduini C, Torti M. The proline-rich tyrosine kinase Pyk2 regulates platelet integrin allbß3 outside-in signaling. J Thromb Haemostasis. 2013;11:345-56.

52. Duong LT, Lakkakorpi PT, Nakamura I, Machwate M, Nagy RM, Rodan GA. PYK2 in osteoclasts is an adhesion kinase, localized in the sealing zone, activated by ligation of $a_{v} \beta_{3}$ integrin, and phosphorylated by src kinase J Clin Invest. 1998;102:881-92.

53. Uyama N, limuro $Y$, Kawada N, Reynaert H, Suzumura K, Hirano T, Kuroda N, Fujimoto J. Fascin, a novel marker of human hepatic stellate cells, may regulate their proliferation, migration, and collagen gene expression through the FAK-PI3K-Akt pathway. Lab Investig. 2012;92:57-71. 
54. Qian Y, Corum L, Meng Q, Blenis J, Zheng JZ, Shi X, Flynn DC, Jiang BH. PI3K induced actin filament remodeling through Akt and p70S6K1: implication of essential role in cell migration. Am J Physiol Cell Physiol. 2004;286:C153-63.

55. Cenni V, Sirri A, Riccio M, Lattanzi G, Santi S, de Pol A, Maraldi NM, Marmiroli S. Targeting of the Akt/PKB kinase to the actin skeleton. Cell Mol Life Sci. 2003;60:2710-20.

56. Shao CP, Lo HR, Lin JH, Hor LI. Regulation of cytotoxicity by quorumsensing signaling in Vibrio vulnificus is mediated by SmcR, a repressor of hlyU. J Bacteriol. 2011;193:2557-65.

Submit your next manuscript to BioMed Central and we will help you at every step:

- We accept pre-submission inquiries

- Our selector tool helps you to find the most relevant journal

- We provide round the clock customer support

- Convenient online submission

- Thorough peer review

- Inclusion in PubMed and all major indexing services

- Maximum visibility for your research

Submit your manuscript at www.biomedcentral.com/submit
Biomed Central 